\title{
A Subacute Motor and Sensory Tractopathy. A New Syndrome
}

\author{
Naheed L Khan ${ }^{1,2 *}$, Marco Catani MD ${ }^{3,4}$, Flavio Dell'Acqua ${ }^{3,4}$, Stephen Connor MD ${ }^{5}$, Kerry Mills6 and P Nigel \\ Leigh $^{7}$
}

${ }^{1}$.Department of Neurology, Maidstone Hospital, Kent, UK

${ }^{2}$ Department of Neurology, Kings College Hospital, London, UK

${ }^{3}$ Institute of Psychiatry Psychology and Neuroscience, King's College London, UK

${ }^{4}$ Department of Neuroimaging Sciences, Institute of Psychiatry, King's College London, UK

${ }^{5}$ Department of Neurophysiology, Kings College Hospital, London, UK

${ }^{6}$ Department of Neurophysiology, Kings College Hospital, London, UK

${ }^{7}$ Department of Medicine, Section of Neurosciences, Brighton and Sussex Medical School, Trafford Centre for Medical Research, University of Sussex, East Sussex, UK

Submission: April 03, 2017; Published: July 31, 2017

*Corresponding author: Naheed Khan, Department of Clinical Neuroscience, $9^{\text {th }}$ Floor Ruskin Wing, King's College Hospital, Denmark Hill, London SE5 9RS, United Kingdom, Email: nkhan1@nhs.net

\begin{abstract}
We describe a new syndrome characterized by sensory symptoms, a repeatedly normal neurological examination with hyperintensity of the corticospinal tracts and reduced myelin content of the posterior internal capsule on functional and MR brain and DTI, pathological prolongation of central motor conduction times and a spontaneous improvement of symptoms. We discuss the diagnoses that have been excluded. The aetiology as yet remains undefined.

Keywords: Corticospinal tract hyperintensity; Central motor conduction times; Tractopathy DTI fMRI
\end{abstract}

\section{Case Report}

A 54year old woman presented with a six-month history of a tingling sensation in the lower back and the toes of both feet that slowly ascended to the hip level. She developed similar symptoms in both hands and described the sensation to be unpleasant, akin to frostbite and as if her hands and fingers were going to explode. There were intermittent spasms in her legs, which felt weak. The spasms interfered with her ability to walk. Fatigue was so significant that she was no longer able to continue in her employment in a managerial post. The medical history was remarkable for a generalized arthralgia and an elevated ESR up to $51 \mathrm{~mm}$. Rheumatological review found no evidence of an inflammatory arthritis. Other medical history included hypertension and a hysterectomy for prolonged menorrhagia due to uterine fibroids.

The patient was born in Jamaica and at the age of 8 years moved to the UK. Whilst living in Jamaica the patient recalled consuming processed cassava infrequently. There were no dietary restrictions. The family history was unremarkable. Both the general and a detailed neurological examination were normal. MRT2 and FLAIR sequences of brain showed a symmetrical increase in signal in the corticospinal tracts through centrum semiovale, the posterior limbs of the internal capsule down to the level of the pons without any associated volume loss (Figure 1). An MRI of the spinal cord was normal. 


\section{Open Access Journal of Neurology \& Neurosurgery}

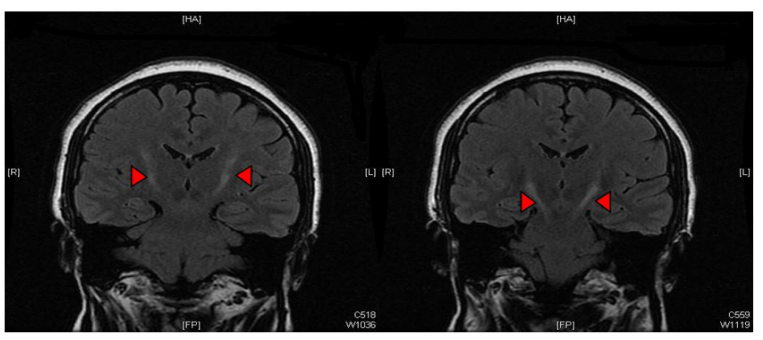

a

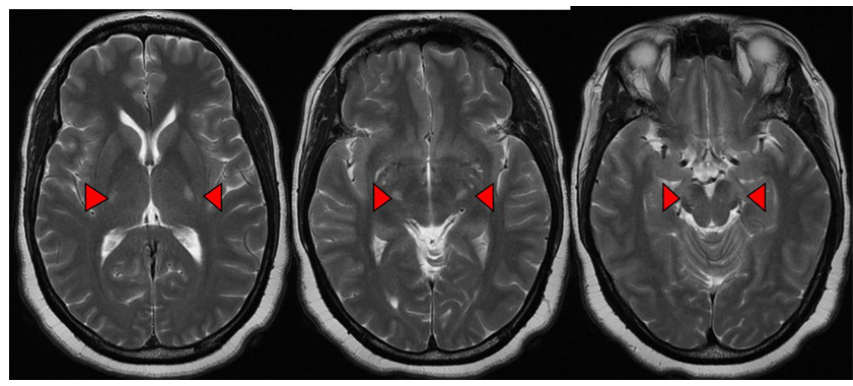

Figure 1: T1 weighted coronal and axial images showing symmetrical increased signal in the corticospinal tracts through the centrum semiovale (a), the internal capsule (b) to the level of the pons (b).

Table 1: Central motor conduction studies of the patient described during the symptomatic and asymptomatic phase in comparison to controls.

\begin{tabular}{|c|c|c|c|c|c|c|}
\hline & \multirow{2}{*}{ Latency (ms) } & \multicolumn{2}{|c|}{ Cortex-muscle } & \multicolumn{3}{|c|}{ СМСТ (ms) } \\
\hline & & A & B & $\mathbf{N}$ & $\mathbf{A}$ & B \\
\hline & $\mathrm{N}$ & & & & & \\
\hline $\mathrm{R} \mathrm{AH}$ & 39 & 55.2 & & 15.9 & 29.4 & 23.7 \\
\hline $\mathrm{R}$ TA & 34 & 47.8 & 44 & 13.8 & & \\
\hline \multirow[t]{2}{*}{ R VM } & 24 & & 28.8 & 13.0 & & \\
\hline & 34.4 & & & & & \\
\hline R ADM & 19 & 27 & 24 & 7.9 & 11.1 & 9.7 \\
\hline L FDI & 21 & 28.2 & & 7.6 & & \\
\hline
\end{tabular}

'N' refers to conduction times in normal subjects [9].

'A' refers to conduction times in the symptomatic phase.

' $\mathrm{B}$ ' refers to conduction times 6 months later during the asymptomatic phase.

R: Right; L: Left; AH: Abductor Hallucis; TA: Tibialis Anterior; VM: Vastus Medialis; ADM: Abductor Digiti Minimii; FDI: First Dorsal Interosseus

Table 2: Upper limb somato sensory evoked potentials (milliseconds).

\begin{tabular}{|c|c|c|c|c|}
\hline & N9 & N13 & N20 & N9-N13 \\
\hline Right median & 9.8 & 15.2 & 21.6 & 5.4 \\
\hline Left median & 10.0 & 15.7 & 22.2 & 5.7 \\
\hline Normals & $9.7 \pm 0.76$ & $13.5 \pm 0.92$ & $19 \pm 1.02$ & $3.8 \pm 0.45$ \\
\hline
\end{tabular}

Central motor conduction times (CMCTs) were prolonged to all muscles sampled (Table 1) but most pronounced in the lower limbs. The degree of slowing of central conduction was in the range that is found in demyelinating disease. Somato sensory evoked potential (SSEPS) were normal in the lower limbs but not in the upper limbs (Table 2). Erb's responses were of normal latency from both arms but Erb's to cervical responses were prolonged bilaterally with normal cervical to cortex responses indicating mild conduction delay in both upper limbs between the brachial plexus and medulla.

EMG and nerve conduction studies were normal. Visual evoked potentials and CSF analysis (microscopy, cytology, glucose, oligoclonal bands) were also normal. The CRP, dsDNA, cardiolipin antibodies, ENA, ANCA, rheumatoid factor, B12 and folate, vitamin A and E levels, serum ACE and chest X-ray, glucose, paraprotein electrophoresis, serum ferritin, copper and caeruloplasmin, treponemal serology, HIV, HTLV1 and 2 antibodies, very long chain fatty acids, peroxisomal function tests and white cell lysosomal enzyme activities and anti GAD antibody were normal or negative. After a six-month interval, a repeat MR of the brain and spinal cord remained unchanged.

More detailed imaging using diffusion tensor imaging (DTI) tractography [1] and mcDespot sequences [2] showed localized abnormalities consistent with myelin loss. Quantification of the myelin content showed more than a 50\% reduction along the fibers of the posterior capsule (Figure 2). The patient was significantly symptomatic for 13 months and during this time the neurological examination remained normal on three further clinical reviews. Symptoms subsequently improved but persisted without any treatment allowing her to return back 
to full time employment. Repeat CMCTs also improved but remained prolonged (Table 1 ).

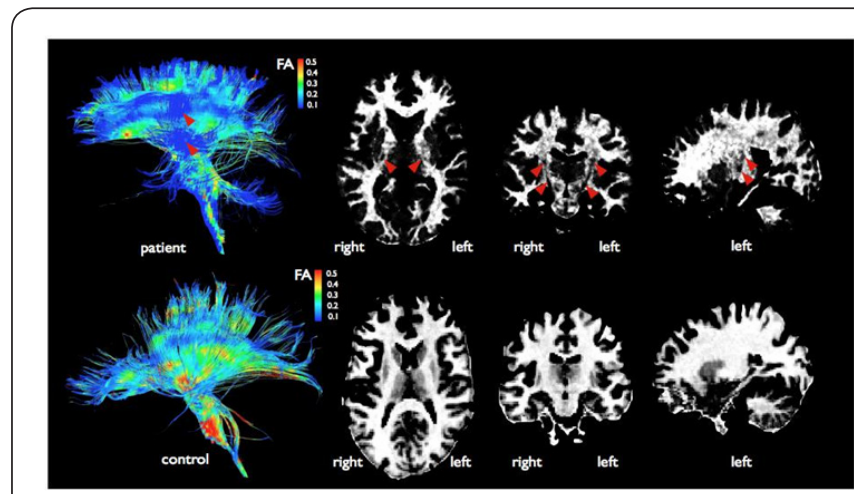

Figure 2: DTI tractography and mcDespot images of the patient (upper row) and a control (lower row) for comparison. The fractional anisotropy (an indirect index of microstructural integrity of axonx/myelin) levels mapped along the tracts of the internal capsule and corona radiata are reduced along the most central fibres (red arrowheads). Quantification of the myelin content shows more than $50 \%$ reduction along the fibers of the posterior capsule (indicated by the red arrowheads on the axial, coronal and sagittal images).

\section{Discussion}

We describe a disorder that to date has not been recorded. Our patient described sensory symptoms in all four limbs and tonic spasms that spontaneously improved 13 months after onset. Symmetrical hyperintensity of the corticospinal tracts on MRI persisted and the central motor conduction times were initially significantly delayed, and subsequently improved, mirroring the patient's symptoms.

Increased T2 signal intensity in the posterior internal capsule has been reported in up to fifty percent of normal subjects and is usually symmetrical, homogenous and without mass effect [3]. The radiological abnormalities in our case extended beyond the internal capsule into each cerebral hemisphere and into the brainstem and this was accompanied by the pathological prolongation of central motor conduction times (to the extent seen in cases of demyelination). Functional MRI of the brain identified a fifty percent reduction of the myelin content of the posterior internal capsules.

The investigative findings are not typical of multiple sclerosis as the signal intensity and myelin loss is confined to the corticospinal tracts alone. The clinical features and the focal and symmetrical hyperintensity of the pyramidal tracts on MR are not typical of the autosomal recessive or X-linked leukodystrophies nor of any of the mitochondrial cytopathies or infectious encephalitides. The entirely normal neurological examination and clinical improvement distinguishes this disease from amyotrophic and primary lateral sclerosis where hyperintensity along the corticospinal tract $[4,5]$ and pathologically prolonged CMCTs is well described.

Konzo is an upper motor neuron syndrome occurring as epidemic outbreaks in Africa where there is famine or warfare
$[6,7]$. In such circumstances inhabitants resort to a diet solely of unprocessed cassava roots (Manihot esculenta) and within weeks of ingestion, present with the abrupt onset of a spastic paraparesis. Our patient did describe the consumption of cassava, however it was ingested in a processed form and last eaten some 45 years before the onset of symptoms. The neurological examination of our subject remained normal throughout the symptomatic period and unlike our case, MRI of the brain and spinal cord in cases of Konzo is normal.

Neurolathyrism can also damage the pyramidal tracts. Consumption of large quantities of the chickpea, Lathyrus sativa which contains high concentrations of the excitotoxic neurotoxin $\beta$-oxalyl-L- $\alpha, \beta$-diaminopropionic acid (ODAP; BOAA) causes a spastic paraparesis $[8,9]$, but there was no such exposure in our patient. There are a number of striking characteristics in our case for which we have no explanation. In particular, there were no pyramidal signs, despite the pathological prolongation of CMCTs at the height of symptoms and the significant loss of myelin in the posterior capsule. In addition, despite the absence of sensory signs, there was a predominance of sensory symptoms in the limbs, especially the lower limbs where the SSEPS were normal. Mild delay of the upper limb SSEPs, bilaterally suggests that the disease process extended beyond the corticospinal tracts, perhaps involving the spinal cord.

The spontaneous improvement of both symptoms and CMCTs excludes a primary degenerative process although quantification of the myelin content shows more than $50 \%$ reduction along the fibers of the posterior capsule. Instead, this patient appears to have developed a hitherto undefined disorder with sub acute onset and gradual recovery, involving central motor and sensory pathway. Long term follow up, collation of other cases, and the characterization of new autoimmune or infective aetiologies may provide clues as to the exact nature of this syndrome.

\section{References}

1. Catani M (2006) Diffusion tensor magnetic resonance imaging tractography in cognitive disorders. Current Opinion Neurology 19(6): 599-606.

2. Deoni SC, Rutt BK, Arun T, Pierpaoli C, Jones DK (2008) Gleaning multicomponent $\mathrm{T} 1$ and $\mathrm{T} 2$ information from steady-state imaging data. Magnetic Resonance Medicine 60(6): 1372-1387.

3. Mirowitz S, Sartor K, Gado M, Torack R (1989) Focal signal-intensity variations in the posterior internal capsule: normal MR findings and distinction from pathologic findings. Radiology 172(2): 535-539.

4. Goodin DS, Rowley HA, Olney RK (1988) Magnetic resonance imaging in amyotrophic lateral sclerosis. Annals of Neurology 23(4): 418-420.

5. Marti-Fabregas J, Pujol J (1990)Selective involvement of the pyramidal tract on magnetic resonance imaging in primary lateral sclerosis. Neurology 40: 1799-1800.

6. Howlett WP, Brubaker GR, Mlingi N, Rosling H (1990) Konzo, an epidemic upper motor neuron disease studied in Tanzania. Brain 113(Pt 1): 223-235.

7. Tylleskär T, Howlett WP, Rwiza HT, Aquilonius SM, Stålberg E, et al. (1993) Konzo: a distinct disease entity with selective upper motor neuron damage. J Neurol Neurosurg Psychiatry 56 (6):638-43. 
8. Spencer PS, Roy DN, Ludolph A, Hugon J, Dwivedi MP, et al. (1986) Lathyrism: evidence for role of the neuroexcitatory aminoacid BOAA. Lancet 2(8515): 1066-1067.
9. Mills KR (1999) Magnetic stimulation of the human nervous system. Oxford University press, UK, pp. 174-176.

\section{Your next submission with Juniper Publishers will reach you the below assets}

- Quality Editorial service

- Swift Peer Review

- Reprints availability

- E-prints Service

- Manuscript Podcast for convenient understanding

- Global attainment for your research

- Manuscript accessibility in different formats

( Pdf, E-pub, Full Text, Audio)

- Unceasing customer service

Track the below URL for one-step submission https://juniperpublishers.com/online-submission.php 